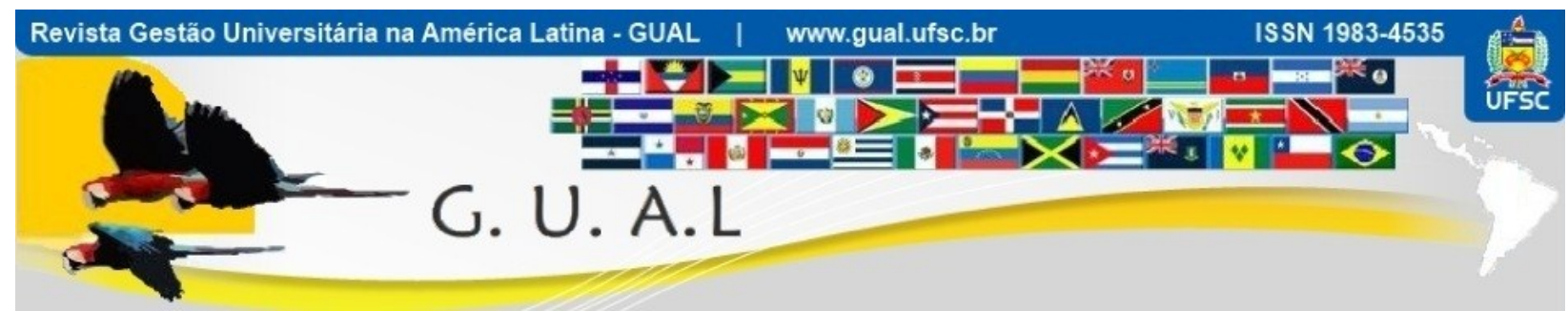

DOI: http://dx.doi.org/10.5007/1983-4535.2013v6n2p33

\title{
GESTÃO AMBIENTAL E SUSTENTABILIDADE EM INSTITUIÇÕES DE ENSINO SUPERIOR: CONSTRUÇÃO DE CONHECIMENTO SOBRE O TEMA
}

\author{
ENVIRONMENTAL MANAGEMENT AND SUSTAINABILITY IN HIGHER \\ EDUCATION INSTITUTIONS: BUILDING KNOWLEDGE ABOUT THE FIELD
}

Leonardo Corrêa Chaves, Mestrando Universidade Federal de Santa Catarina - UFSC leonardomg@gmail.com

Claudio Luiz de Freitas, Mestrando Universidade Federal de Santa Catarina - UFSC claudio.freitas@posgrad.ufsc.br

Leonardo Ensslin, Doutor Universidade Federal de Santa Catarina - UFSC leonardoensslin@gmail.com

Elisete Dahmer Pfitscher, Doutora Universidade Federal de Santa Catarina - UFSC elisete.dahmer@ufsc.br

Sérgio Murilo Petri, Doutor Universidade Federal de Santa Catarina - UFSC smpetri@gmail.com

Sandra Rolim Ensslin, Doutora Universidade Federal de Santa Catarina - UFSC sensslin@gmail.com

Recebido em 08/julho/2012

Aprovado em 05/fevereiro/2013

Sistema de Avaliação: Double Blind Review 


\title{
RESUMO
}

A atual pressão mundial pela conscientização ambiental atingiu diferentes instituições tais como empresas, instituições filantrópicas e universidades. Estas, como formadoras de opinião e prestadoras de serviços à sociedade, transmitem a conscientização ambiental por meio da gestão socioambiental. Desta forma, o objetivo do trabalho, de natureza exploratóriodescritiva, é construir o conhecimento sobre o tema gestão sócio ambiental em instituições de ensino, utilizando o Knowledge Development Process - Constructivist (ProKnow-C) como instrumento de intervenção. Como resultados identificou-se um Portfólio Bibliográfico (PB) composto por 14 artigos e, através deste $\mathrm{PB}$, constatou-se que os periódicos International Journal of Sustainability in Higher Education e Journal of Cleaner Production são os mais alinhados ao tema. O artigo mais citado do PB é Toward sustainable management: the University of Michigan Housing Division's approach. O autor Shriberg, M. é o autor com mais trabalhos no PB e os autores Velazquez, L. e Munguia, N. são os mais citados no PB. A palavra-chave mais utilizada no PB é Higher Education seguida por sustainable development, sustainability e Environmental Management.

Palavras-chave: Gestão. Social. Ambiental. Universidades.

\begin{abstract}
The current world pressure for environmental awareness affected different institutions such as companies, charities and universities. These institutions, as opinion makers and providers of services for the society, transmit environmental awareness through social and environmental management. Thus, the objective of this study, which has an exploratory and descriptive nature, is to build knowledge about the subject social and environmental management in education institutions, by using the Knowledge Development Process - Constructivist (ProKnow-C) as intervention tool. The results allowed us to identify a Bibliographic Portfolio (BP) composed of 14 articles and, through this BP, we found the most highlighted: (i) International Journal of Sustainability in Higher Education and the Journal of Cleaner Production as the outstanding journals; (ii) Toward sustainable management: the University of Michigan Housing Division's approach as the most cited article in the BP; (iii) Shriberg, M. as the author who has the highest number of articles in the PB and the authors Velazquez, L. and Munguia, N. as authors who have the highest number of citations in the references of the BP. The most used keyword in PB is Higher Education, followed by sustainable development, sustainability and Environmental Management.
\end{abstract}

Keywords: Management. Social. Environmental. Higher education. Universities. 


\section{INTRODUÇÃO}

A temática gestão ambiental e sustentabilidade são recorrentes e vem sendo amplamente discutidas nos mais diversos segmentos e fóruns, evidenciando sua inter e multidisciplinaridade, expressa pelos diferentes atores ligados a essas discussões (NICOLAIDES, 2006).

Seja tratando o tema em um contexto geral ou abordando aspectos específicos que envolvem a temática, o assunto é pauta das discussões políticas, corporativas, econômicas, sociais e acadêmicas (NICOLAIDES, 2006).

Desta forma, o assunto gestão socioambiental e sustentabilidade ganhou expressão, relevância e significado a partir da conscientização e de uma gradual mudança (BERINGER, 2007), de comportamento e cultura (SAMMALISTO; BRORSON, 2008), da sociedade, em relação às necessidades de preservação e uso racional dos recursos naturais, de forma a promover qualidade de vida presente e futura.

Assim, pensar a organização, atualmente, significa pensar além dos processos, rotinas, estratégias e metas, pensar a inserção da organização na sociedade e os impactos que suas atividades podem provocar ao ambiente, visualizando o desenvolvimento sustentável da instituição e da sociedade a qual está inserida (SHRIBERG, 2002b).

Seguindo esta lógica e pensando as universidades como organizações prestadoras de serviços, devem ser preocupações destas, os impactos causados ao meio ambiente e à sociedade, decorrentes de suas ações e das atividades de seus agentes (NICOLAIDES, 2006; SAMMALISTO; BRORSON, 2008; SMYTH et al., 2010; HASAN; MORRISON, 2011).

Recai, portanto, sobre estas instituições, o compromisso primeiro com a promoção do desenvolvimento sustentável da instituição e da sociedade (SHRIBERG, 2002a; MOORE, 2005; BERINGER, 2007; RICHARDSON; A.LYNES, 2007; HASAN; MORRISON, 2011), visto que as universidades são espaços formadores de opinião, pautados pela formação crítica, política, social e humanitária (SHRIBERG, 2002b; MOORE, 2005; SMYTH et al., 2010).

Neste sentido, dada a contribuição que se espera das universidades para com a sociedade a qual se insere, cabe conhecer as formas como estas tratam a questão socioambiental e a sustentabilidade, no contexto de suas atividades. Para tanto, alguns instrumentos são disponibilizados pelas instituições, tais como relatórios de gestão, relatórios de sustentabilidade), balanço social e pesquisas científicas (SHRIBERG, 2002a; VELAZQUEZ et al., 2006; SAMMALISTO; BRORSON, 2008). 
Este último instrumento de divulgação, as pesquisas científicas, relata o tratamento dispensado pelas universidades em relação às práticas socioambientais e de sustentabilidade, a partir de uma ótica sustentada por referencial teórico e métodos científicos, destacando a contribuição acadêmica das ações da instituição.

Desta forma, compreender a gestão socioambiental e a sustentabilidade das instituições de ensino superior, a partir dos relatos contidos nos trabalhos científicos, torna-se importante, pois é a partir da literatura científica que se torna a possível a formação de opinião nas universidades.

Para tanto, o mapeamento é uma forma para tal compreensão, uma vez que apresenta o que tem sido tratado na literatura sobre a temática gestão socioambiental e sustentabilidade no âmbito das instituições de ensino superior, a partir de uma seleção estruturada, com destaque para os trabalhos de maior reconhecimento e relevância científica, de acordo com os critérios definidos pelos autores deste trabalho.

Assim, diante do apresentado, a problemática que norteia este trabalho, é expressa no seguinte questionamento: "Como construir conhecimento sobre o tema gestão socioambiental e sustentabilidade em instituições de ensino superior?"

Assim, diante do apresentado, o objetivo deste trabalho é construir conhecimento sobre o tema gestão socioambiental e sustentabilidade em instituições de ensino superior.

Para tanto, os seguintes objetivos específicos são delineados: (i) selecionar um portfólio bibliográfico de reconhecida relevância científica sobre a temática gestão socioambiental e sustentabilidade em instituições de ensino superior; (ii) identificar os autores, periódicos, artigos e palavras-chave mais relevantes.

Para o êxito dos objetivos propostos e a consequente resposta da pergunta de pesquisa, o presente trabalho estrutura-se da seguinte forma: Esta seção inicial, que apresenta o tema, problema e objetivos de pesquisa; a seção 2, que aborda o referencial teórico que dá suporte as discussões dos resultados; a seção 3, que apresenta a metodologia da pesquisa; a seção 4 que expõe os resultados e discussões deste trabalho; a seção 5 que aborda as conclusões e considerações finais dos pesquisadores; e as referências que suportaram o desenvolvimento desta pesquisa. 


\section{REFERENCIAL TEÓRICO}

Esta seção aborda uma breve noção a respeito da pesquisa científica, visando suporte à seleção de trabalhos com reconhecimento científico e a bibliometria; e uma noção sobre gestão ambiental, foco temático da pesquisa.

\subsection{Pesquisa científica}

Com o objetivo de proporcionar o desenvolvimento histórico, social, cultural, intelectual, econômico e tecnológico para a comunidade científica e sociedade civil, de forma geral, a pesquisa científica constitui-se como produto da ação humana, em seu anseio de compreender e solucionar seus problemas (RICHARDSON, 1999).

Por meio de seus resultados, as pesquisas científicas evidenciam e contribuem com a resolução de problemas cotidianos e a melhoria da qualidade de vida, através da inovação; do desenvolvimento de tecnologias e soluções; e da disseminação do conhecimento.

Como produto da ação humana, o ato de pesquisar é amparado por métodos que guardem o padrão e o rigor científico. Conforme destaca Richardson (1999) há uma diferença significativa entre o que é publicado e o processo percorrido até o resultado final divulgado, uma vez que várias das ações empreendidas no desenvolvimento da pesquisa, por vezes não são incluídas no relatório final.

Com isso, a divulgação científica, embora expresse o resultado final da pesquisa, guarda em si o processo de realização da pesquisa, evidenciado pela trajetória metodológica utilizada pelos pesquisadores e pelo alcance dos resultados da pesquisa, imprimindo sobre ela validade e credibilidade. A divulgação da pesquisa científica é, portanto, legitimadora dos métodos e resultados da pesquisa, permitindo a ampliação e do conhecimento científico. (TAHAI; RIGSBY, 1998; SILVA; MENEZES; PINHEIRO, 2003).

Para além da responsabilidade atribuída à divulgação científica de assegurar a credibilidade da pesquisa e, de certa forma evidenciar o potencial de qualidade do relatório final divulgado, é necessário que o pesquisador esteja atento para os métodos e procedimentos que são empregados na condução da pesquisa. Neste sentido, respaldar-se em um referencial teórico adequadamente selecionado e alinhado a pesquisa é aspecto fundamental para o sucesso da publicação.

Com o objetivo de garantir um referencial teórico suportado por publicações de impacto, com reconhecimento científico e que expressem o estado da arte sobre o tema 
pesquisado, um dos instrumentos disponíveis para o pesquisador é o Knowledge Development Process - Constructivist (ProKnow-C), que auxilia o pesquisador na seleção de um portfólio bibliográfico que atenda aos critérios apontados anteriormente, garantindo robustez ao desenvolvimento de sua pesquisa.

\subsection{Gestão ambiental}

A gestão ambiental é um dos, senão o mais importante, instrumento para o desenvolvimento sustentável, estando, porém, vinculado a normas emanadas do poder público, e agências reguladoras (DIAS, 2006).

Assim, conforme aponta Berté (2009, p.53) "no terreno da gestão ambiental, poder público e sociedade civil não se opõem, mas se complementam.”.

Desta forma, a gestão ambiental reveste-se de extensão e complexidade e deve ser tratada em seu contexto amplo, não se limitando a aspectos isolados (PHILIPPI JR.; BRUNA, 2009).

Logo, a gestão ambiental consiste em uma estrutura, que sob a ótica sistêmica, agrega planejamento, responsabilidades, práticas, procedimentos e processos a fim de que haja uma mobilização interna e externamente a organização para se possa atingir a qualidade ambiental almejada. (TINOCO e KRAEMER, 2008)

Neste sentido, o objetivo da gestão ambiental é promover o equilíbrio entre os aspectos sociais, econômicos, ambientais e políticos, inerentes a existência e ao conjunto de relações humanas, mantendo-se atentos aos normativos emanados do poder público e entidades com poder para emitir normatizações a respeito. (DIAS, 2006; FERREIRA et al, 2008; BONISSONI et al, 2009).

Observa-se, então, o significado da gestão ambiental no âmbito governamental, destacando-se a necessidade de atuação dos organismos governamentais, não apenas na função de reguladores e fiscalizadores, mas como agentes ativos e participativos do processo de gestão ambiental, assumindo também o compromisso social e ambiental.

Sob essa ótica, observa-se ainda a inserção da gestão ambiental no contexto das instituições de ensino superior, pautada pela peculiaridade e necessidade que tais entidades de se posicionarem de forma crítica, conscientizadora e atuante, numa postura ativa e norteadora de políticas e ações de caráter socioambiental, conforme destacam (SHRIBERG, 2002a), 
Boff, Oro e Beuren (2008); Arvidsson (2004); Sammalisto e Brorson (2008), Velazquez et al., (2006) e Smyth et al., (2010).

A respeito da gestão ambiental em instituições de ensino superior, Boff, Oro e Beuren (2008) destacam que esta proporciona benefícios ao meio ambiente, a medida em que a agressão ao ambiente e o consumo inadequado de recursos é reduzido. E, por outro lado, promove benefícios econômicos e estratégicos para a instituição, através da redução de gastos e melhoria da imagem da instituição perante os stakeholders.

Para Bertoli e Ribeiro (2006) e Smyth et al., (2010) ressaltam, entretanto, que as instituições de ensino superior devem observar que a gestão ambiental produz mais resultados estratégicos, em longo prazo, do que benefícios econômicos em curto prazo.

\section{METODOLOGIA}

A metodologia adota para a pesquisa aborda o enquadramento do trabalho quanto as abordagens, lógica, objetivos e procedimentos adotados, além de apresentar os procedimentos para seleção do portfólio bibliográfico.

\subsection{Enquadramento metodológico}

A metodologia adotada para condução da pesquisa constitui-se como descritiva, uma vez que se descreve características do Portfólio Bibliográfico. (RICHARDSON, 1999). Também é exploratória, pois através do procedimento adotado e do portfólio definido buscase a ampliação dos conhecimentos dos pesquisadores sobre a temática específica, aprofundando tal conhecimento por meio da análise bibliométrica do portfólio (GIL, 2007).

Quanto à natureza do artigo, trata-se como teórico-ilustrativo tendo em vista que o objetivo é apresentar o modelo bibliométrico por vias da ilustração do tema gestão sócio ambiental em instituições de ensino superior.

A lógica da pesquisa é indutiva porque não se tinha uma estimativa dos resultados do estudo antes a pesquisa (IUDÍCIBUS, 2007).

A pesquisa constitui-se de fontes primária e secundária. A fonte primária é caracterizada, nesta pesquisa, pelas delimitações dos pesquisadores utilizadas no desenvolvimento do processo de seleção do portfólio bibliográfico, ao passo que a fonte secundária caracteriza-se pelo portfólio selecionado que é público e consta nas bases de dados. (RICHARDSON, 1999; GIL, 2007) 
A abordagem do problema é qualitativa pela presença de valores e preferências dos pesquisadores e quantitativa pela contagem de variáveis durante a bibliometria. (RICHARDSON, 1999)

A pesquisa é bibliográfica, uma vez que a seleção do portfólio ocorreu em bases internacionais, acessíveis pelo Portal de Periódicos da CAPES.

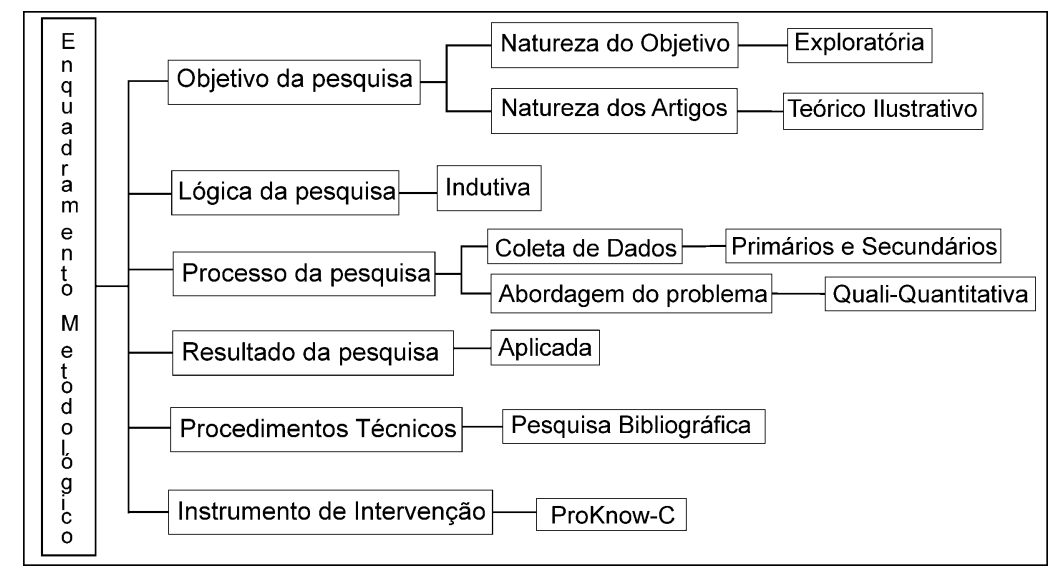

Figura 1 Enquadramento Metodológico.

Fonte: Adaptado de Tasca et al, 2010.

O instrumento de intervenção utilizado é o ProKnow-C (Knowledge Development Process - Constructivist), desenvolvido sob a ótica construtivista do LabMCDA (TASCA et al., 2010; AFONSO et al., 2011; ROSA et al., 2011; VALMORBIDA et al., 2012), com o objetivo de evidenciar um portfólio bibliográfico selecionado de forma estruturada, contemplando como reconhecimento científico, alinhamento do tema e robustez na formação do referencial teórico das pesquisas e a bibliometria das variáveis já citadas.

\subsection{Procedimento de coleta dos dados}

Para a seleção do portfólio bibliográfico, adotou-se o Knowledge Development Process - Constructivist (ProKnow-C), conforme detalhado na

Figura 2.

O processo ProKnow-C constituiu-se da definição dos eixos e palavras-chave que formaram o comando de busca a aplicado as bases ISIKNOWLEDGE, SCOPUS e EBSCO. As etapas do processo compreenderam a eliminação de trabalhos que não se caracterizavam como artigos científicos e de trabalhos localizados em duplicidade; a leitura e identificação de títulos alinhados a proposta temática do trabalho, conforme definição dos pesquisadores; e a verificação do reconhecimento científico dos trabalhos através do número de citações no Google Acadêmico. 


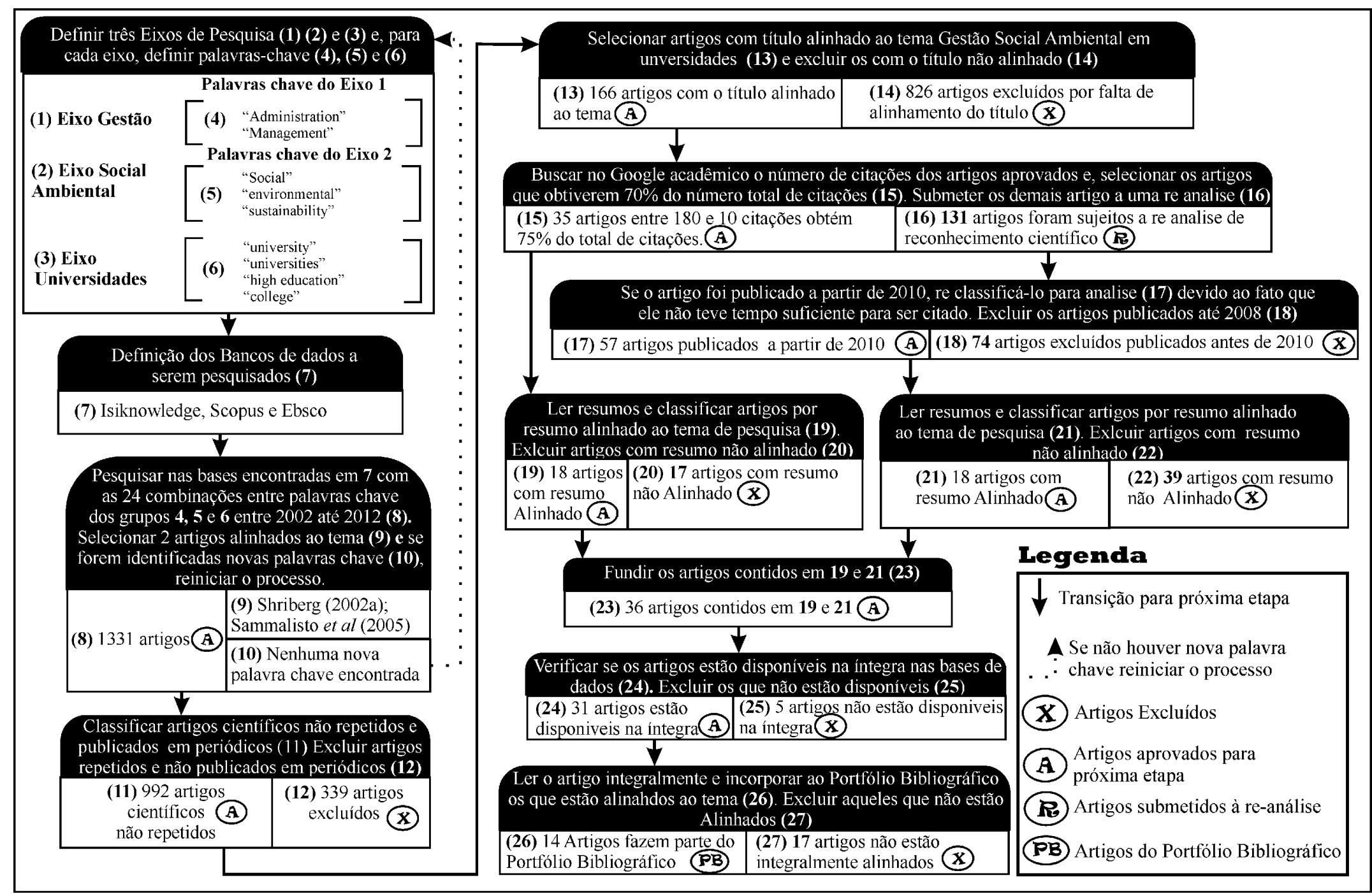

Figura 2 Processo se seleção de portfólio bibliográfico Fonte: Adaptado de Afonso et al., 2011. 


\section{GESTÃO AMBIENTAL E SUSTENTABILIDADE EM INSTITUIÇÕES DE ENSINO SUPERIOR: CONSTRUÇÃO DE CONHECIMENTO SOBRE O TEMA \\ DOI: http://dx.doi.org/10.5007/1983-4535.2013v6n2p33}

Após a seleção dos trabalhos de maior reconhecimento científico, o processo compreendeu a análise de alinhamento a proposta conceitual da pesquisa, por meio da leitura dos resumos dos trabalhos selecionados até essa etapa e a re análise dos trabalhos que, por terem sido publicados recentemente, não tiveram tempo suficiente para se destacarem em número de citações.

Do processo de análise e re análise dos resumos, selecionaram-se 31 trabalhos finais que estavam disponíveis, em sua versão completa, no Portal de Periódicos da CAPES, para a leitura completa. Nesta etapa selecionou-se 14 trabalhos, que atendiam ao alinhamento conceitual definido pelos pesquisadores, para integrar o portfólio bibliográfico sobre gestão socioambiental e sustentabilidade em instituições de ensino superior, conforme destacado no

Quadro 1.

1. ALSHUWAIKHAT, H. M.; ABUBAKAR, I. An integrated approach to achieving campus sustainability: assessment of the current campus environmental management practices. Journal of Cleaner Production, v. 16, n. 16, p. 1777-1785, 2008.

2. BERINGER, A. The Lüneburg Sustainable University Project in international comparison: An assessment against North American peers. International Journal of Sustainability in Higher Education, v. 8, n. 4, p. 446-461, 2007.

3. CLARKE, A.; KOURI, R. Choosing an appropriate university or college environmental management system. Journal of Cleaner Production, v. 17, n. 11, p. 971-984, Jul 2009.

4. HASAN, M.; MORRISON, A. Current University Environmental Management Practices. Journal of Modern Accounting \& Auditing, v. 7, n. 11, p. 1292-1300, 2011.

5. KRIZEK, K. J.; NEWPORT, D.; WHITE, J.; TOWNSEND, A. R. Higher education's sustainability imperative: How to practically respond? International Journal of Sustainability in Higher Education, v. 13, n. 1, p. 19-33, 2012.

6. MOORE, J. Seven recommendations for creating sustainability education at the university level: A guide for change agents. International Journal of Sustainability in Higher Education, v. 6, n. 4, p. 326-339, 2005.

7. NICOLAIDES, A. The implementation of environmental management towards sustainable universities and education for sustainable development as an ethical imperative. International Journal of Sustainability in Higher Education, v. 7, n. 4, p. 414-424, 2006.

8. RICHARDSON, G. R.; A.LYNES, J. K. Institutional motivations and barriers to the construction of green buildings on campus: A case study of the University of Waterloo, Ontario. International Journal of Sustainability in Higher Education, v. 8, n. 3, p. 339-354, 2007.

9. SAMMALISTO, K.; BRORSON, T. Training and communication in the implementation of environmental management systems (ISO 14001): a case study at the University of Gavle, Sweden. Journal of Cleaner Production, v. 16, n. 3, p. 299-309, 2008.

10. SHRIBERG, M. Institutional assessment tools for sustainability in higher education: Strengths, weaknesses, and implications for practice and theory. Higher Education Policy, v. 15, n. 2, p. 153-167, $2002 \mathrm{a}$. 11. SHRIBERG, M. Toward sustainable management: the University of Michigan Housing Division's approach. Journal of Cleaner Production, v. 10, n. 1, p. 41-45, 2002 b.

12. SMYTH, D. P.; FREDEEN, A. L.; BOOTH, A. L. Reducing solid waste in higher education: The first step towards 'greening' a university campus. Resources Conservation and Recycling, v. 54, n. 11, p. 1007-1016, Sep 2010.

13. VELAZQUEZ, L.; MUNGUIA, N.; PLATT, A.; TADDEI, J. Sustainable university: what can be the matter? Journal of Cleaner Production, v. 14, n. 9-11, p. 810-819, 2006.

14. ZHANG, N.; WILLIAMS, I. D.; KEMP, S.; SMITH, N. F. Greening academia: Developing sustainable waste management at Higher Education Institutions. Waste Management, v. 31, n. 7, p. 1606-1616, Jul 2011.

Quadro 1 Portfólio Bibliográfico

Fonte: Dados da pesquisa, 2012. 


\section{ANÁLISE BIBLIOMÉTRICA}

Para os quatorze trabalhos selecionados no referencial teórico, procedeu-se a análise bibliométrica, observando os autores, periódicos, palavras-chave e trabalhos de maior destaque entre os apresentados no portfólio e os citados pelo portfólio.

\subsection{Periódicos de destaque}

Em relação aos periódicos, a

Figura 3 evidencia os periódicos que mais se destacaram no portfólio bibliográfico, os periódicos que mais se destacaram entre os citados pelo portfólio bibliográfico e o destaque dos periódicos do portfólio bibliográfico em relação ao fator de impacto nas bases ISIKNOWLEDGE e SCOPUS.

\subsubsection{Periódicos de destaque no Portfólio Bibliográfico}

Observa-se, em relação à

Figura 3, no gráfico A, o destaque para os periódicos: Journal of Cleaner Production e International Journal of Sustainability in Higher Education. Dos quatorze trabalhos selecionados no portfólio dez foram publicados nesses periódicos, sendo cinco em cada um deles.

O Journal of Cleaner Production, que publicou cinco dos quatorze trabalhos do portfólio, possui ISSN 0959-6526 e se constitui como fórum interdisciplinar internacional para o intercâmbio de informações e pesquisas direcionadas ao progresso de sociedades sustentáveis. (JOURNAL OF CLEANER PRODUCTION, 2012)

O International Journal of Sustainability in Higher Education, com cinco artigos entre os quatorze do portfólio, possui ISSN 1467-6370, caracterizando-se por ser a primeira publicação científica a abordar a temática de sustentabilidade especificamente para universidades, com foco na divulgação científica e de informações sobre sustentabilidade para instituições de ensino superior. (INTERNATIONAL JOURNAL OF SUSTAINABILITY IN HIGHER EDUCATION, 2012)

O International Journal of Sustainability in Higher Education, pelo próprio título já evidencia alinhamento com a temática pesquisada e, acredita-se, por esta razão o destaque no número de publicações do portfólio. 


\section{GESTÃO AMBIENTAL E SUSTENTABILIDADE EM INSTITUIÇÕES DE ENSINO SUPERIOR: \\ CONSTRUÇÃO DE CONHECIMENTO SOBRE O TEMA \\ DOI: http://dx.doi.org/10.5007/1983-4535.2013v6n2p33}

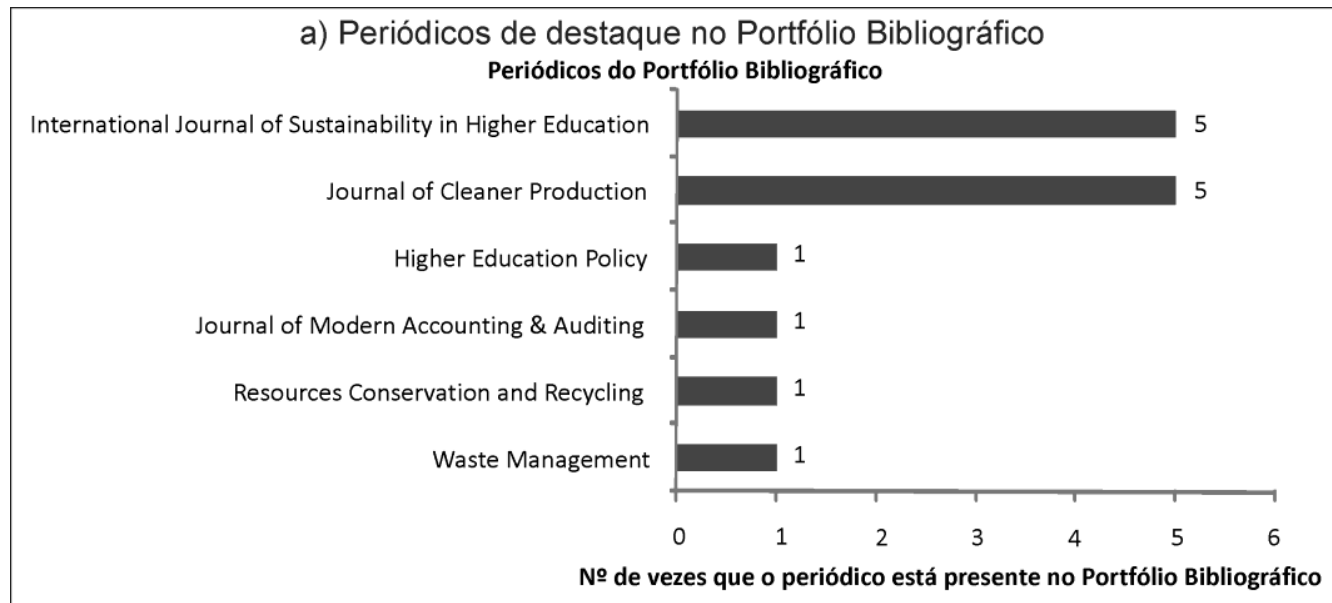

b) Periódicos de destaque das referências do Portfólio Bibliográfico

Periódicos das referência do portfólio bibliográfico

International Journal of Sustainability in Higher Education Journal of Cleaner Production Resources, Conservation and Recycling Waste Management Higher Education Policy Waste Management and Research Planning for Higher Education Journal of Environmental Education European Management Journal Local Environ

Journal of Environmental Management Journal of Economic Perspectives

International Journal of Operations \& Production Management International Journal of Environmental Education and Information Higher Education Ecological Economics Demais Journals citados no portfólio (50)

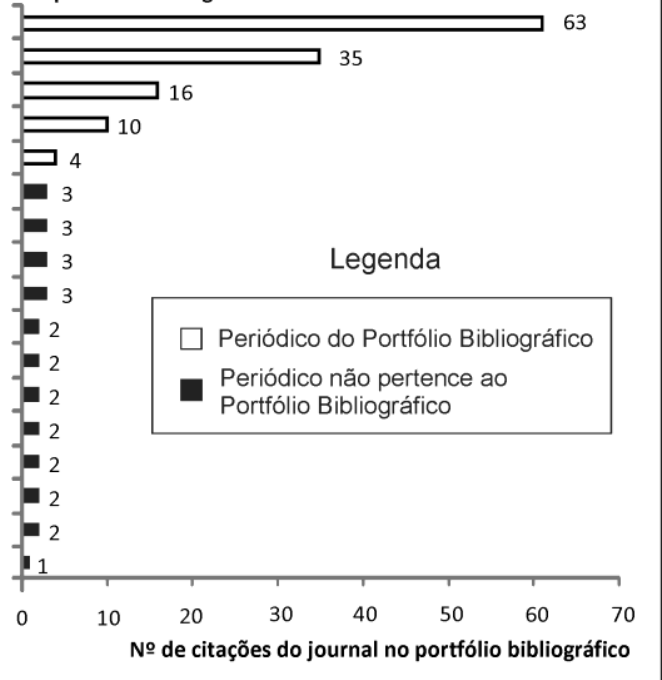

c) Periódicos do Portfólio de destaque em fator de impacto

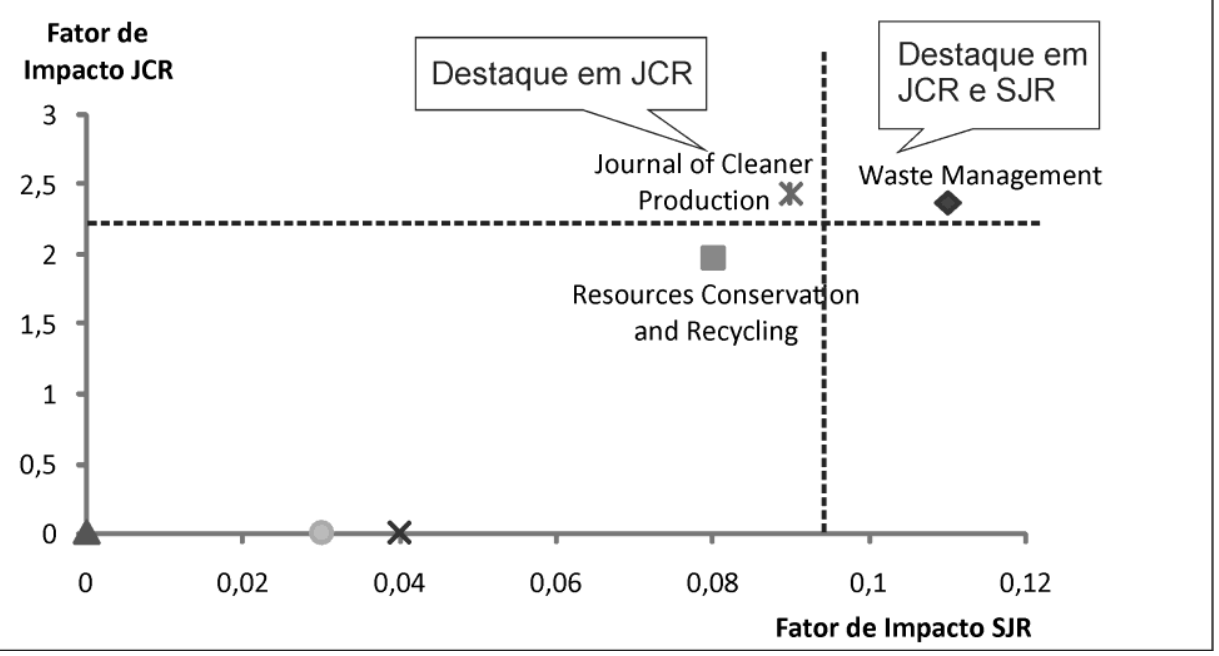

Figura 3 Análise de destaque e relevância dos periódicos que compõem o portfólio e dos periódicos que foram citados pelo portfólio Fonte: Dados da pesquisa, 2012. 
4.1.2 Periódicos de destaque das referências do Portfólio Bibliográfico

Em relação aos periódicos utilizados para publicar os trabalhos citados nas referências do portfólio, conforme Gráfico B, da

Figura 3, observa-se uma composição maior de títulos, observando, entretanto o alinhamento dos títulos à questão da sustentabilidade, gestão ambiental e ensino superior.

De tal gráfico observam-se cinco periódicos com maior destaque: Higher Education Policy, com quatro citações; Waste Management, com dez citações; Resources, Conservation and Recycling, com dezesseis citações; Journal of Cleaner Production, com trinta e cinco citações; e International Journal of Sustainability in Higher Education, com sessenta e três citações. Todos os cinco periódicos de maior destaque nas referências também compõem os periódicos do portfólio.

\subsubsection{Periódicos do Portfólio de destaque em fator de impacto}

Salienta-se que no Gráfico B, da

Figura 3, os periódicos de maior destaque foram o International Journal of Sustainability in Higher Education e o Journal of Cleaner Production. Ambos com destaque também no portfólio bibliográfico, conforme Gráfico A, da mesma figura. Porém, no Gráfico B nota-se um alinhamento maior do International Journal of Sustainability in Higher Education, nas referências do portfólio.

Dados os destaques apresentados, buscou-se aprofundar a compreensão desses destaques no portfólio, analisando o fator de impacto, nas bases ISIKNOWLEDGE e SCOPUS, conforme mostra o Gráfico C, da

Figura 3.

Da leitura do Gráfico C, destacam-se dois periódicos: Journal of Cleaner Production e Waste Management. O Journal of Cleaner Production se destacou no fator de impacto JCR, da ISIKNOWLEDGE com JCR de 2,430. Já o Waste Management, destacou-se tanto no JCR, quanto no SJR, da SCOPUS. Para este periódico o JCR foi de 2,358 e o SJR foi de 0,11.

O Waste Management possui ISSN 0956-053X, e é uma publicação internacional com foco na gestão de resíduos sólidos, voltada para a publicação de trabalhos científicos originados das diferentes áreas de formação acadêmica. (WASTE MANAGEMENT, 2012)

Apesar de estar contido entre os cinco periódicos de maior destaque das referências do portfólio e de possuir um SJR de 0,11 e, portanto, maior que o Journal of Cleaner Production 
$(0,09)$, o Journal of Cleaner Production possui um JCR maior e é destaque tanto no portfólio, que figura como o periódico que mais publicou sobre o tema (Gráfico A,

Figura 3), quanto nas referências do portfólio que figura como segundo periódico que mais publicou sobre a temática gestão ambiental e sustentabilidade em instituição de ensino (Gráfico B,

Figura 3).

\subsection{Artigos de destaque}

Ainda analisando o reconhecimento dos trabalhos que compõem o portfólio e dos trabalhos citados nas referências do portfólio, procedeu-se a análise comparativa do número de citações dos artigos do portfólio bibliográfico no Google Acadêmico e nas referências do portfólio, conforme apresenta a

Figura 4.

\subsubsection{Artigos de destaque do Portfólio bibliográfico}

Da análise comparativa entre o número de citações dos artigos do portfólio bibliográfico no Google Acadêmico e o número de citações dos artigos do portfólio nas referências do próprio portfólio (Gráfico A,

Figura 4), constatou-se destaque no Google Acadêmico para o trabalho "Institutional assessment tools for sustainability in higher education: Strengths, weaknesses, and implications for practice and theory" de Shriberg (2002b), com 82 citações; e para o "Seven recommendations for creating sustainability education at the university level: A guide for change agents.", de Moore (2005), com 53 citações.

Identificou-se, porém, o artigo "Sustainable university: What can be the matter?", de Velazquez et al (2006) com destaque no número de citações no Google Acadêmico (43) e nas referências do portfólio bibliográfico (3), sendo considerado, em termos de citações conjuntas, o trabalho de maior destaque.

\subsubsection{Artigos de destaque das referências do Portfólio Bibliográfico}

Conforme o Gráfico B da

Figura 4, o trabalho de Shriberg (2002b) apresenta 82 citações e também pertence ao Portfólio Bibliográfico. Cabe salientar que os artigos das referências do Portfólio não são 
incorporados ao portfólio por não serem necessariamente alinhados ao tema. Neste caso, considerou-se no gráfico Gráfico B da

Figura 4, o artigo "Green campuses: The road from little victories to systemic transformation" com o título alinhado a proposta conceitual da pesquisa e poderia ser incorporado ao Portfólio desde que fosse aprovado nos filtros sequenciais estabelecidos pelo ProKnow-C. 


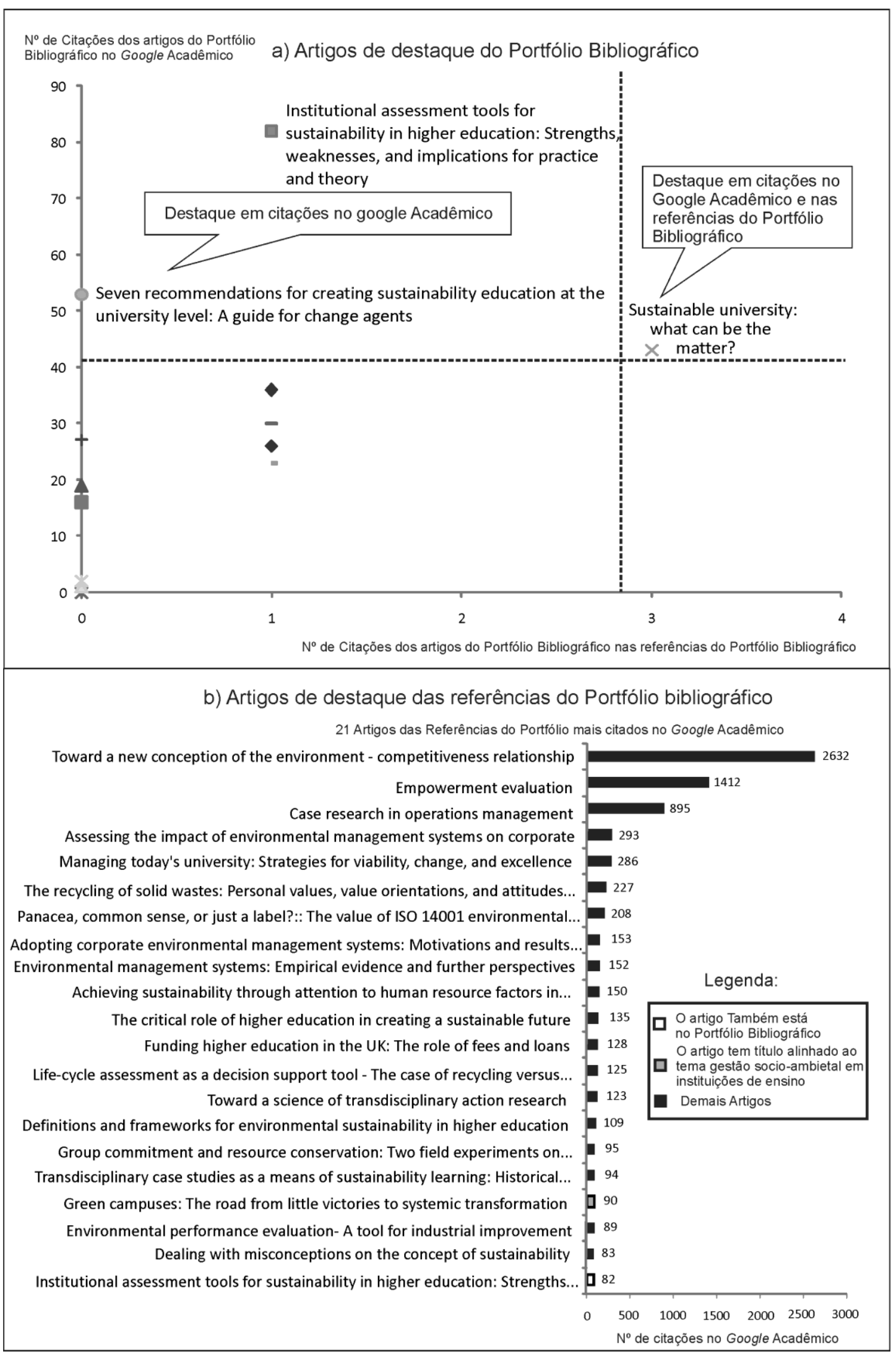

Figura 4 Análise de destaque e relevância dos artigos citados pelo portfólio bibliográfico Fonte: Dados da pesquisa, 2012. 


\subsection{Autores de destaque}

Nesta seção, analisar-se-á a relevância dos autores do Portfólio Bibliográfico, em relação ao número de trabalhos, e das respectivas referências, em relação ao número de vezes que o autor aparece conforme ilustra a

Figura 5.

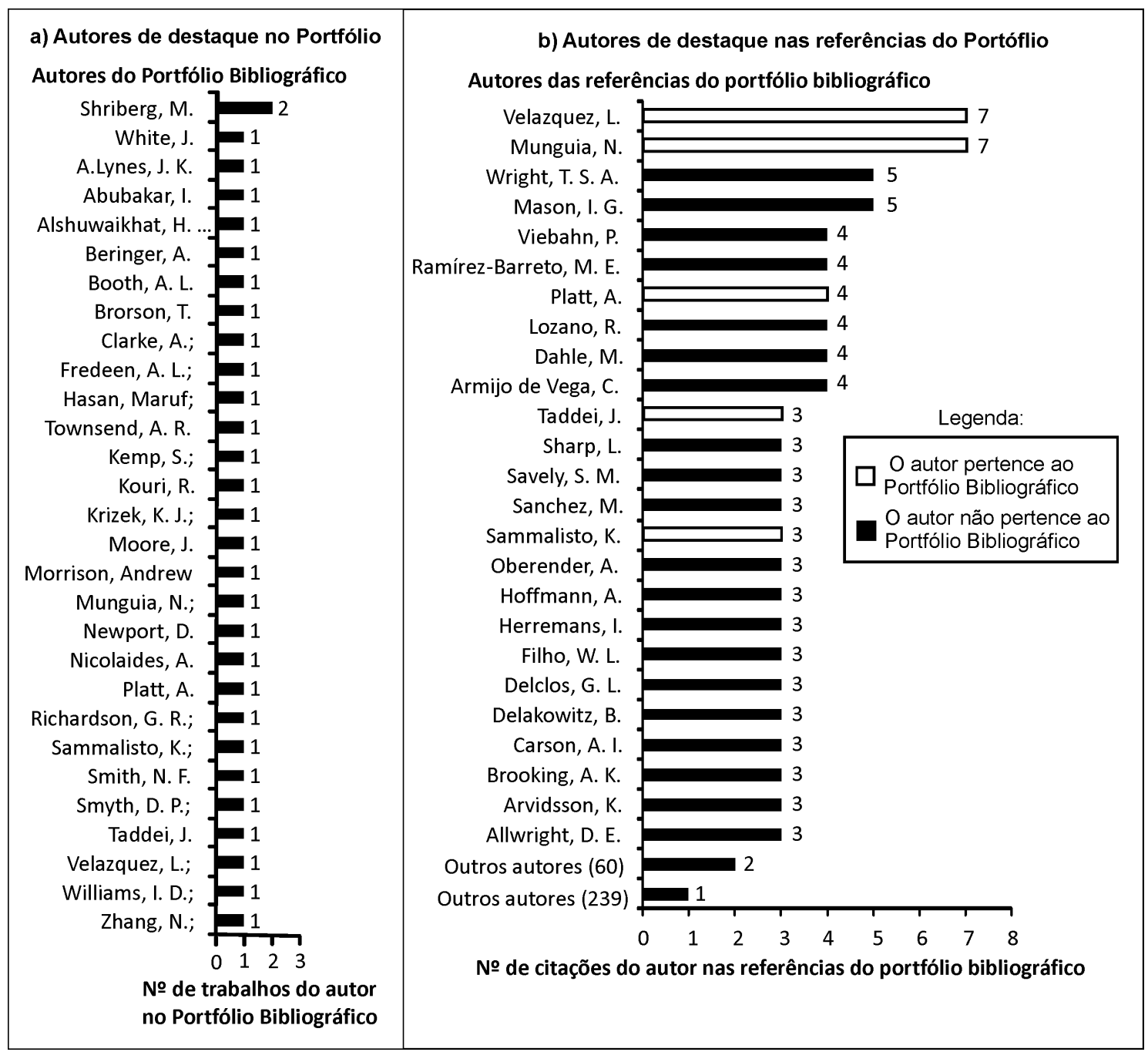

Figura 5 Análise de destaque e relevância dos autores citados no portfólio bibliográfico.

Fonte: Dados da pesquisa, 2012.

\subsubsection{Autores de destaque no Portfólio Bibliográfico}

Observa-se que, conforme o gráfico a da

Figura 5, o trabalho de Shiriberg se destaca no portfólio com dois trabalhos, sendo o destaque entre os quatorze trabalhos selecionados, conforme o gráfico a da

Figura 5. 
4.3.2 Autores de destaque das referências do Portfólio Bibliográfico

Ao analisar as referências que foram citadas pelo portfólio, observa-se, outros autores em destaque, conforme evidencia a

Figura 5. Da referida figura, observa-se que o autor de maior destaque no portfólio, Shriberg, não assume a mesma condição nas referências, embora tenha recebido duas citações dentre as referências do portfólio.

Também na

Figura 5 fica evidente o destaque principal das referências do portfólio por conta de Velazquez, L. e Munguia, N., com o maior número de citações nas referências do portfólio.

O destaque nas referências do portfólio, para Velazquez e Munguia, juntamente com Platt, Taddei e Sammalisto, que estão entre os autores do portfólio, confirma e evidencia o alinhamento do portfólio selecionado, dado pelos pesquisadores durante o processo de seleção.

\subsection{Palavras-chave de destaque}

Além das análises de destaque e reconhecimento científico de autores e periódicos no portfólio e nas referências do portfólio, buscou-se, também, compreender a inserção das palavras-chave no portfólio, conforme demonstra a Figura 6. 


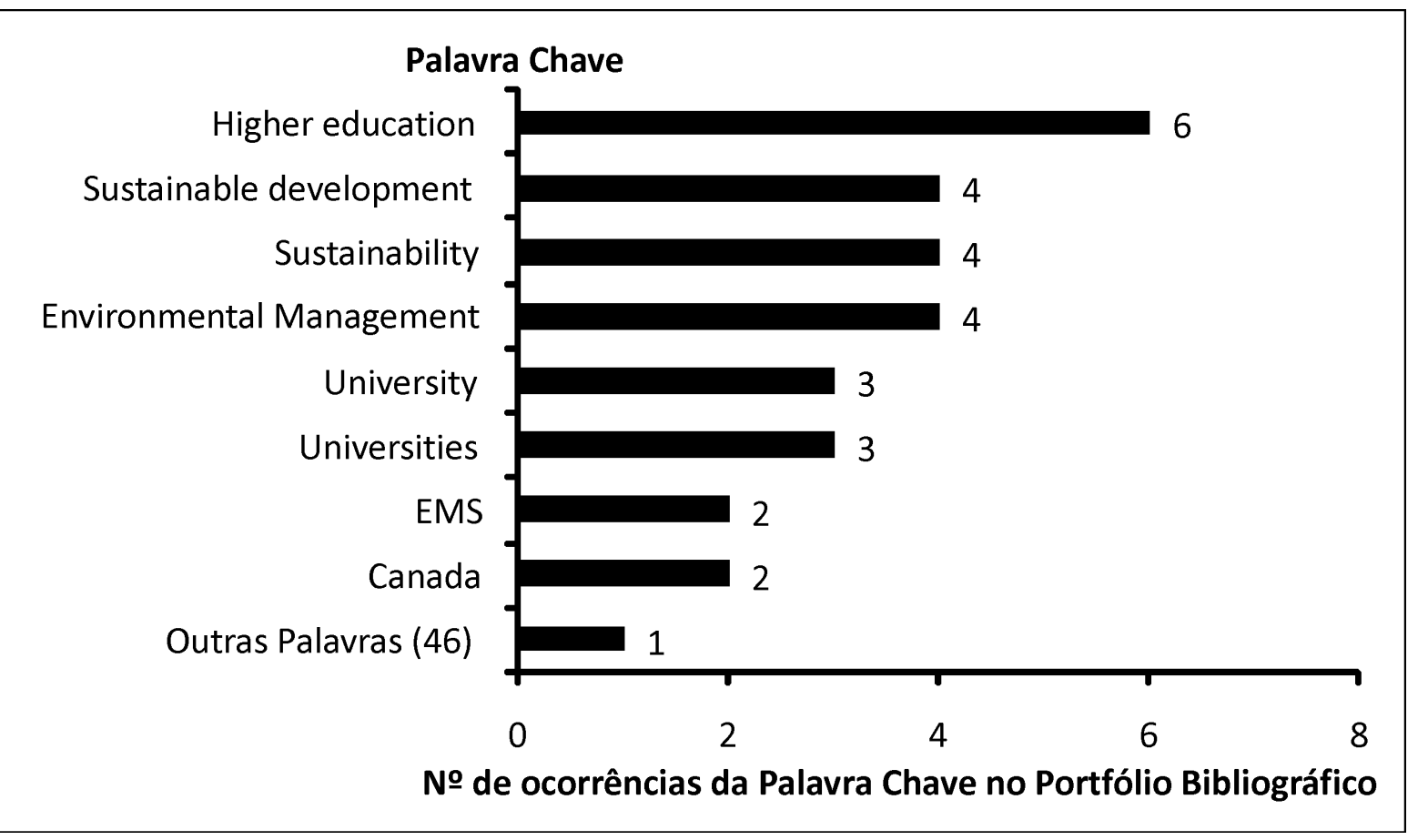

Figura 6 Análise de destaque das palavras-chave dos artigos citados pelo portfólio bibliográfico. Fonte: Dados da pesquisa, 2012.

A Figura 6 aponta o alinhamento das palavras-chave do portfólio com a temática em estudo, sendo que a palavra-chave que mais apareceu foi "Higher education". Observa-se ainda que dado o tema da pesquisa, gestão ambiental e sustentabilidade em instituições de ensino superior, uma das palavras apresentadas na Figura 6 destoa do escopo da pesquisa: "Canada".

\section{CONSIDERAÇÕES FINAIS}

A necessidade de conhecimento sobre determinado tema de pesquisa, conduz o pesquisador a aprimorar os métodos e formas de condução da pesquisa. Neste sentido definir um processo estruturado de seleção de referências que garanta a qualidade, alinhamento da proposta conceitual, rigor e reconhecimento científico dos trabalhos selecionados, faz-se necessário.

Frente a isso, questionou-se: "Como construir conhecimento sobre o tema gestão socioambiental e sustentabilidade em instituições de ensino superior?"

Para responder a essa questão, utilizou-se o instrumento Knowledge Development Process - Constructivist (ProKnow-C) para selecionar os artigos evidenciados no

Quadro 1, selecionados para compor o portfólio, bem como para a análise bibliométrica, conforme apresentado na seção 0 . 


\section{GESTÃO AMBIENTAL E SUSTENTABILIDADE EM INSTITUIÇÕES DE ENSINO SUPERIOR: \\ CONSTRUCCÃO DE CONHECIMENTO SOBRE O TEMA \\ DOI: http://dx.doi.org/10.5007/1983-4535.2013v6n2p33}

Com o suporte da análise bibliométrica o alinhamento dos trabalhos do portfólio foi confirmado, visto o destaque dos periódicos citados no portfólio e nas referências do portfólio, assim como o reconhecimento dos periódicos em relação ao seu fator de impacto nas bases ISIKNOWLEDGE e SCOPUS.

Os periódicos mais presentes das referências do PB são International Journal of Sustainability in Higher Education e Journal of Cleaner Production com 63 e 35 ocorrências respectivamente. Estes 2 periódicos também são os que mais estão presentes no $\mathrm{PB}$, cada um abrange 5 dos 14 artigos. O artigo mais citado foi Toward sustainable management: the University of Michigan Housing Division's approach com 82 citações. O artigo Sustainable university: what can be the matter? Apresenta 43 citações e é citado em outros 3 artigos do PB. O autor que mais trabalhos possui no portfólio bibliográfico é Shriberg com 2 artigos. Os autores que mais são citados pelos artigos do $\mathrm{PB}$, que inclusive pertencem ao $\mathrm{PB}$, são Velazquez, L. e Munguia, N. com 7 citações cada. A palavra-chave mais utilizada pelos artigos do PB é Higher Education seguida por sustainable development, sustainability e Environmental Management.

Ao analisar o destaque dos autores no portfólio e nas referências do portfólio, bem como o destaque das palavras-chave e dos trabalhos, também se confirma o alinhamento do portfólio selecionado, visto que alguns dos autores que se destacam nas referências do portfólio compõem o referido portfólio, assim como as palavras-chave refletem a adequação do tema e os artigos demonstram reconhecimento científico, quando verificado o número de citações que receberam, conforme apresentado na seção 4.

Desta forma, apesar de apresentar limitações quanto à amostra, já que a seleção limitou-se aos trabalhos disponibilizados pelo portal de periódicos da CAPES, e as delimitações estabelecidas pelos pesquisadores, o presente trabalho atingiu o objetivo proposto, que consistia em selecionar um portfólio teórico sobre gestão ambiental e sustentabilidade em instituições de ensino, verificando a sua estrutura, em termos de autores e veículos de divulgação mais relevantes dentre os trabalhos selecionados.

Dadas às limitações da pesquisa, sugere-se para futuros trabalhos a expansão das bases de seleção, além das disponíveis no portal de periódicos da CAPES, além da análise de conteúdo dos trabalhos a fim de aprofundar e confirmar os dados aqui apresentados, dando credibilidade maior ao alinhamento conceitual definido pelos pesquisadores no processo de seleção do portfólio. 


\section{REFERÊNCIAS}

AFONSO, M. H. F.; SOUZA, J. V.; ENSSLIN, S. R.; ENSSLIN, L. Como construir conhecimento sobre o tema de pesquisa? Aplicação do processo proknow-c na busca de literatura sobre avaliação do desenvolvimento sustentável. Revista de Gestão Social e Ambiental, v. 5, n. 2, 2011.

ALSHUWAIKHAT, H. M.; ABUBAKAR, I. An integrated approach to achieving campus sustainability: assessment of the current campus environmental management practices. Journal of Cleaner Production, v. 16, n. 16, p. 1777-1785, 2008. ISSN 0959-6526.

ARVIDSSON, K. Environmental management at Swedish universities. International Journal of Sustainability in Higher Education. v.5 n. 1, 2004, pp. 91-99

BERINGER, A. The Lüneburg Sustainable University Project in international comparison: An assessment against North American peers. International Journal of Sustainability in Higher Education, v. 8, n. 4, p. 446-461, 2007.

CLARKE, A.; KOURI, R. Choosing an appropriate university or college environmental management system. Journal of Cleaner Production, v. 17, n. 11, p. 971-984, Jul 2009. ISSN 0959-6526.

BERTÉ, R. Gestão socioambiental no Brasil. São Paulo, Saraiva, 2009.

BERTOLI, A.L.; RIBEIRO, M.S. 2006. Passivo ambiental: estudo de caso da Petróleo Brasileiro S.A. - Petrobrás. A recuperação ambiental nas demonstrações contábeis, em consequência dos acidentes ocorridos. Revista de Administração Contemporânea - RAC, v. 10, n. 2, p. 117-136, abr./jun.

BOFF, L. M; ORO, I. M; BEUREN, I.M. Gestão ambiental em Instituição de Ensino Superior na visão de seus dirigentes. Revista de Contabilidade da UFBA. v.2 n.1, 2008. p. $4-13$

BONISSONI, R.M. et al. A gestão ambiental de uma fábrica de bebida energética por meio da sustentabilidade ambiental. In: CONGRESSO UFSC DE CONTROLADORIA E FINANÇAS. 3., 2009, Florianópolis. Anais... Florianópolis: Departamento de Ciências Contábeis/UFSC, 2009.

DIAS, R. Gestão ambiental: Responsabilidade social e sustentabilidade. São Paulo, Atlas, 2006.

FERREIRA, L. F. et al. Contabilidade ambiental sistêmica. In: CONGRESSO UFSC DE CONTROLADORIA E FINANÇAS. 2., 2008, Florianópolis. Anais... Florianópolis: Departamento de Ciências Contábeis/UFSC, 2008.

GIL, A. C.. Como elaborar projetos de pesquisa. 4. ed. São Paulo: Atlas, 2007. 
HASAN, M.; MORRISON, A. Current University Environmental Management Practices. Journal of Modern Accounting \& Auditing, v. 7, n. 11, p. 1292-1300, 2011. ISSN 15486583.

INTERNATIONAL JOURNAL OF SUSTAINABILITY IN HIGHER EDUCATION. Aims and Scope Disponível em: $<$ http://www.journals.elsevier.com/journal-of-cleanerproduction/> Acesso em: 30 abr. 2012.

IUDÍCIBUS, S. Teoria da Contabilidade. São Paulo: 2004.

JOURNAL OF CLEANER PRODUCTION. Aims and Scope Disponível em:

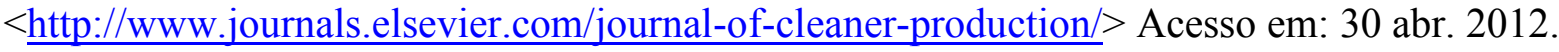

KRIZEK, K. J. et al. Higher education's sustainability imperative: How to practically respond? International Journal of Sustainability in Higher Education, v. 13, n. 1, p. 19$33,2012$.

MOORE, J. Seven recommendations for creating sustainability education at the university level: A guide for change agents. International Journal of Sustainability in Higher Education, v. 6, n. 4, p. 326-339, 2005.

NICOLAIDES, A. The implementation of environmental management towards sustainable universities and education for sustainable development as an ethical imperative.

International Journal of Sustainability in Higher Education, v. 7, n. 4, p. 414-424, 2006.

RICHARDSON, G. R.; A.LYNES, J. K. Institutional motivations and barriers to the construction of green buildings on campus: A case study of the University of Waterloo, Ontario. International Journal of Sustainability in Higher Education, v. 8, n. 3, p. 339354, 2007.

RICHARDSON, R. J. Pesquisa social: métodos e técnicas. 3. ed. São Paulo: Atlas, 1999.

SAMMALISTO, K.; BRORSON, T. Training and communication in the implementation of environmental management systems (ISO 14001): a case study at the University of Gavle, Sweden. Journal of Cleaner Production, v. 16, n. 3, p. 299-309, 2008. ISSN 0959-6526.

SHRIBERG, M. Institutional assessment tools for sustainability in higher education: Strengths, weaknesses, and implications for practice and theory. Higher Education Policy, v. 15 , n. 2, p. 153-167, 2002a.

Toward sustainable management: the University of Michigan Housing Division's approach. Journal of Cleaner Production, v. 10, n. 1, p. 41-45, 2002b. ISSN 0959-6526.

SMYTH, D. P.; FREDEEN, A. L.; BOOTH, A. L. Reducing solid waste in higher education: The first step towards 'greening' a university campus. Resources Conservation and Recycling, v. 54, n. 11, p. 1007-1016, Sep 2010. ISSN 0921-3449. 
PHILIPPI JR., A; BRUNA, G. C. Política e gestão ambiental. In: PHILIPPI JR, A; ROMÉRO, M. A; BRUNA, G. C. (Org.). Curso de gestão ambiental. Barueri: Manole, 2009.

ROSA, F. S.; ENSSLIN, S. R.; ENSSLIN, L.; LUNKES, R. J. Gestão da evidenciação ambiental: um estudo sobre as potencialidades e oportunidades do tema. Engenharia Sanitária Ambiental, v. 16, n. 1, p. 157-166, 2011.

SAMMALISTO, K; ARVIDSSON, K. Environmental management in Swedish higher education Directives, driving forces, hindrances, environmental aspects and environmental co-ordinators in Swedish universities. International Journal of Sustainability in Higher Education Vol. 6 No. 1, 2005 pp. 18-35

SILVA, E. L.; MENEZES, E. M.; PINHEIRO, L. V. Avaliação da produtividade científica dos pesquisadores nas áreas de ciências humanas e sociais aplicadas. Informação e Sociedade. v. 13, n. 2, p. 193-222, 2003.

TAHAI, A.; RIGBSY, J. Information processing using citation to investigate journal influence in accounting. Information Processing \& Management. v. 34, n. 2, p. 341-359, 1998.

TASCA, J. E.; ENSSLIN, L.; ENSSLIN, S. R.; ALVES, M. B. M. An approach for selecting a theoretical framework for the evaluation of training programs. Journal of European Industrial Training, v. 34, n. 7, p. 631-655, 2010.

TINOCO, J. E. P; KRAEMER, M. E. P. Contabilidade e gestão ambiental. 2ed. São Paulo, Atlas, 2008.

WASTE MANAGEMENT. Aims and Scope. Disponível em:

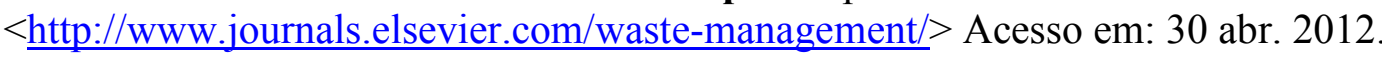

VALMORBIDA, S. M. I.; ENSSLIN, S. R.; ENSSLIN, L.; BORTOLUZZI, S. C. Gestão Pública com foco em resultados: Evidenciação de oportunidades de pesquisa. CAPAccounting and Management, v. 5, n. 5, p. 126-136, 2012.

VELAZQUEZ, L. et al. Sustainable university: what can be the matter? Journal of Cleaner Production, v. 14, n. 9-11, p. 810-819, 2006. ISSN 0959-6526.

ZHANG, N. et al. Greening academia: Developing sustainable waste management at Higher Education Institutions. Waste Management, v. 31, n. 7, p. 1606-1616, Jul 2011. ISSN 0956$053 X$. 